\title{
Exaggerated placental site reaction: case report of a rare benign trophoblastic lesion
}

\author{
Archana Shetty, Aparna Narasimha*, Jyalakshmi V. J.
}

Department of Pathology, Sapthagiri Institute of Medical Sciences and Research Centre, Bangalore, India

Received: 17 August 2015

Accepted: 03 September 2015

\author{
*Correspondence: \\ Dr. Aparna Narasimha, \\ E-mail: sonrichie14@gmail.com
}

Copyright: (C) the author(s), publisher and licensee Medip Academy. This is an open-access article distributed under the terms of the Creative Commons Attribution Non-Commercial License, which permits unrestricted non-commercial use, distribution, and reproduction in any medium, provided the original work is properly cited.

\begin{abstract}
Exaggerated placental site is a rare benign non-neoplastic trophoblastic lesion in which the intermediate trophoblastic cells extensively infiltrate into the endometrium and the underlying myometrium. The importance of this lesion lies in that the cells of this lesion display an identical morphological and immunophenotypic profile to the intermediate trophoblastic cells found placental site trophoblastic tumour, which are closely related neoplastic lesions Also differentials for this lesion are placental site nodule, choriocarcinoma and epithelioid trophoblastic tumour all of which have varied lines of treatment and interventions. We present a rare case of an exaggerated placental site reaction in a lady, who was in her first trimester of pregnancy and presented with signs of a septic abortion.
\end{abstract}

Keywords: Exaggerated placental site, intermediate trophoblast, Myometrium, Placental site nodule, Ki- 67

\section{INTRODUCTION}

Exaggerated placental site (EPS) is a benign nonneoplastic lesion characterized by an increased number of implantation site intermediate trophoblastic cells that extensively infiltrate the endometrium and myometrium. Although it was called as "syncytial endometritis" in the past, the World health Organization introduced the term" Exaggerated placental site", because the lesion is noninflammatory, not confined to the endometrium and the constituent cells were not syncitial. ${ }^{1}$ The importance of identifying this lesion lies in the fact that it may be difficult to distinguish it from other trophoblastic neoplastic lesions, which warrant aggressive treatment and follow up.

\section{CASE REPORT}

A 35 year old female, who was in the $10^{\text {th }}-12^{\text {th }}$ week of pregnancy whose gravid was 5 and parity was 2 came to the emergency section of Gynecology with severe lower abdominal pain, fever and chills with vaginal bleeding. On examination, her temperature was 102 degree F, with a heart rate of 110 beats per minute. The patient was sweating profusely with evidence of vaginal bleeding. Suspecting signs of a septic abortion, an emergency curettage was performed and the material sent for histopathological examination.

Microscopy of the curettage showed small and medium sized chorionic villi, many of which were avascular and hyalinised (Figure 1A). Perivillous fibrin deposition was seen. Benign hyper secretory endometrial glands and fragments of decidualised tissue were seen. Also seen were strips of myometrial muscle fibres showing invasion by intermediate trophoblastic cells many of which were multinucleated with bizarre nuclei (Figure 1B, Figure 2A and $2 \mathrm{~B}$ ).

Focal areas of endometrial stroma and glands also showed such entrapped cells. No hyaline nodules, necrosis was noted (Figure 3A). Ki - 67 labelling index done showed a mitotic activity of less than $1 \%$ (Figure 3B). A final diagnosis of exaggerated placental site with products of conception was conferred. 


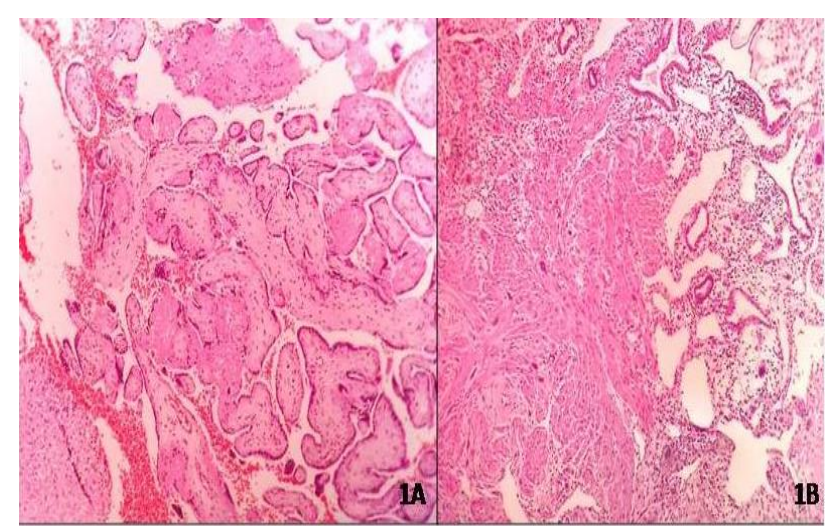

Figure 1: Microphotograph showing A) small to medium sized a vascular chorionic villi and areas of haemorrhage [H\&E,X100] B) endometrial glands and myometrial tissue with trophoblastic invasion [H\&E,X100].

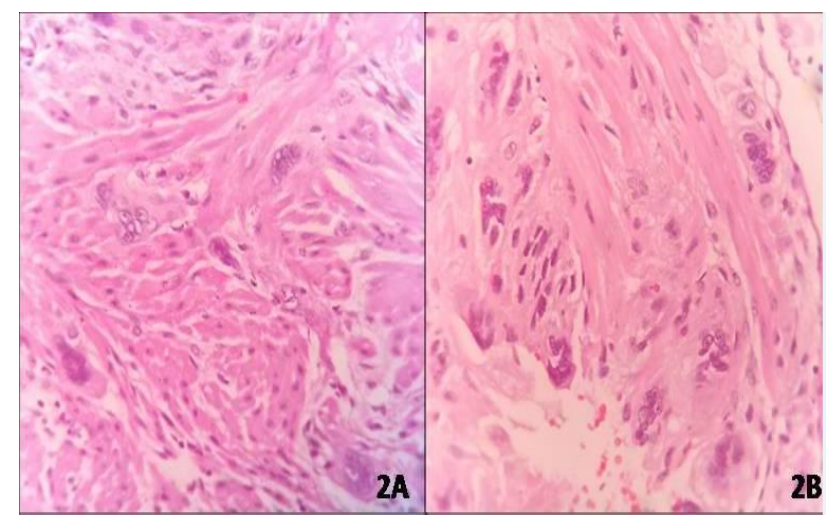

Figure 2: Microphotographs showing myometrial muscle fibres invaded by multinucleated, bizarre intermediate trophoblastic cells [H\&E,X1000].

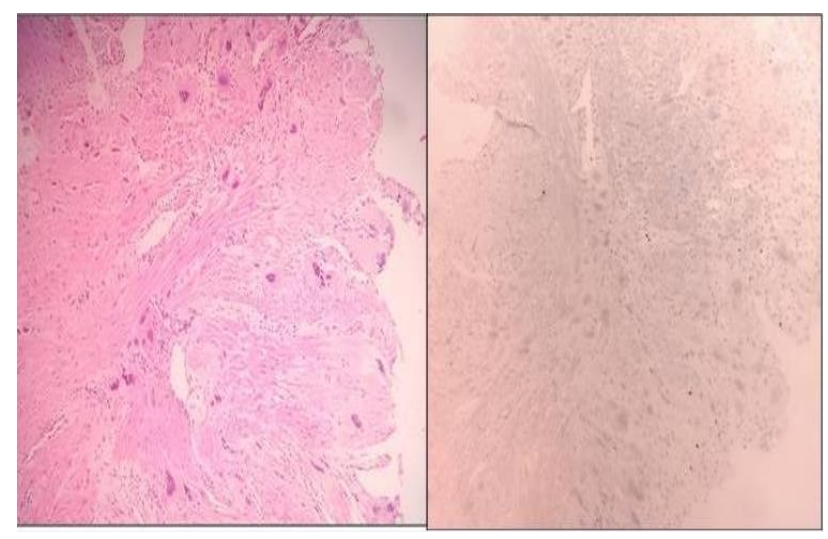

Figure 3: Microphotographs showing A) myometrial muscle fibres invaded by multinucleated, bizarre intermediate trophoblastic cells [H\&E,X100] B) corresponding area showing negativity for the Ki-67 antibody staining [Ki-67,X100].

\section{DISCUSSION}

Intermediate trophoblast was called as such because it was considered intermediate in differentiation between cytotrophoblast and syncytiotrophoblast Implantation site intermediate trophoblast is important for the maintenance of pregnancy; during early gestation as it infiltrates the decidua and invades the myometrium and spiral arteries, a physiologic process required to establish the maternalfetal circulation. Physiologically only the upper half of the myometrium is invaded by these cells during the first trimester and regress progressively over a period of time. ${ }^{2}$ When the intermediate trophoblast infiltrates exaggeratedly into the myometrium, failing to regress or involute the condition is called as an EPS.

EPS may follow normal pregnancy, ectopic pregnancy as in fallopian tube, abortus or molar pregnancy. Our case was a case of first trimester abortion. ${ }^{1,3}$ Pathologists are generally hesitant to make a diagnosis of intrauterine pregnancy merely by the presence of extravillous trophoblastic cells and in the absence of villi. These are highly differentiated, probably already degenerative, extravillous trophoblastic cells. Wandering cells, migratory cells, megalokaryocytes and diplokaryocytes are the other names used for them. Increased incidence of syncytial knotting points to abnormal villous shapes, found usually under hypoxic conditions. ${ }^{4}$

On microscopy, especially in curettage samples reporting EPS, based on histopathological features alone is a dilemma, as till date there is no exact information about the proportion of intermediate trophoblast that has to invade the myometrium in the implantation site at different stages of pregnancy. However the importance lies in distinguishing this lesion from the other gestational lesions like Placental site nodule [PSN], Placental site trophoblastic tumour [PSST]. Clinically evidence of pregnancy and at the same time no mass in the myometrium suggests an EPS, while a mass in the myometrium usually months after a term pregnancy favours a PSTT. ${ }^{1}$ PSN represents remnants of placental site tissue that has failed to involute. Although PSN occurs in the reproductive age group, a temporal association with recent pregnancy is usually lacking and often the time interval between pregnancy and diagnosis of PSN can be several years three months to eight years]. ${ }^{4,5}$ EPS is also distinguished from placental site nodule in that the intermediate trophoblastic cells are laid out in nests and cords and by the absence of hyaline nodules on microscopy. 3,5 In our case the patient had signs of pregnancy and scanning showed no mass in the myometrium, this along with the microscopic findings favoured a EPS over a PSN.

Histopathological features alone are not sufficient to differentiate between the EPS, PSN and PSTT. All these lesions are CKAE1/3, EMA and $\mathrm{BHcG}$ positive indicating an intermediate trophoblastic origin. ${ }^{6,7}$ Recent studies have shown that Ki- 67 specific (MIB -1) 
antibody is the most useful as it is less than $1 \%$ in EPS and increased in all other differentials of this lesion Our case showed a Ki- 67 labelling index of less than $1 \%$. In PSTT, mean Ki -67 staining is $14 \%$ of total specimen area, when compared with $69 \%$ of total specimen area in choriocarcinoma. ${ }^{8}$ In choriocarcinoma histopathology will often show features of molar pregnancy, unlike EPS. A cytogenetic non fluorescent in-situ hybridization [NISH] study by Faul et al in cases of exaggerated placental site trophoblast indicated that often bizarre nuclei found in these lesions are polyploidy or aneuploidy, perhaps arising by cell fusion or endoreduplication of chromosomes. ${ }^{4}$ The intermediate trophoblast in our lesion stained negatively favouring an EPS. The documented treatment for EPS is ablation following which there is complete recovery. ${ }^{7}$

\section{CONCLUSION}

Exaggerated placental site is a benign trophoblastic lesion, without any risk of persistent gestational trophoblastic diseases. However, the awareness of this rare entity is essential as it must be distinguished from other borderline and malignant lesions like placental site nodule, Placental site trophoblastic tumour and Choriocarcinoma which require an aggressive treatment protocol unlike this lesion. More literature and documentation of cases is required to establish the criteria of diagnosing this lesion confidently on the basis of morphology alone.

Funding: No funding sources Conflict of interest: None declared

Ethical approval: Not required

\section{REFERENCES}

1. Ozdemir O, Sari ME, Selimova V, Ilgin BU, Atalay CR. A case report of complete mole with co-existent exaggerated placental site reaction and review of the literature. Niger Med J. 2014;55(2):180-2.

2. Erdogan NY, Kara M. Exaggerated placental site with term pregnancy. Pakistan Journalof Medical Sciences Quarterly. 2012;28(4):977-8.

3. Choi JJ, Emmadi R. Incidental placental site nodule in a fallopian tube. Int J Surg Pathol. 2014;22(1):902.

4. Benischke K, Kaufmann P. In Trophoblastic neoplasms. Pathology of the human placenta $4^{\text {th }}$ edition, Germany, Springer. 2000:754-767.

5. Jacob S, Mohapatra D. Placental site nodule: a tumor-like trophoblastic lesion. Indian J Pathol Microbiol. 2009;52(2):240-1.

6. O'Neill CJ, Cook I, McCluggage WG. Postcesarean delivery uterine diffuse intermediate trophoblastic lesion resembling placental site plaque. Hum Pathol. 2009;40(9):1358-60.

7. Chen B, Cheng C, Chen W. Transformation of a post-cesarean section placental site nodule into a coexisting epithelioid trophoblastic tumor and placental site trophoblastic tumor: a case report. Diagnostic Pathology. 2013;8:85.

8. Behtash, N, Karimi Zarchi M. Placental site trophoblastic tumor. Journal of Cancer Research \& Clinical Oncology. 2008;134(1):1-6.

Cite this article as: Shetty A, Narasimha A, Jayalakshmi VJ. Exaggerated placental site reaction: case report of a rare benign trophoblastic lesion. Int $\mathbf{J}$ Reprod Contracept Obstet Gynecol 2015;4:1647-9. 